\title{
TRPM4 Conductances in Thalamic Reticular Nucleus Neurons Generate Persistent Firing during Slow Oscillations
}

\author{
${ }^{\circ}$ John J. O’Malley, ${ }^{1,2}{ }^{\circledR}$ Frederik Seibt, ${ }^{1}{ }^{\circledR}$ Jeannie Chin, ${ }^{3}$ and ${ }^{\circledR}$ Michael Beierlein ${ }^{1,2}$ \\ ${ }^{1}$ Department of Neurobiology \& Anatomy, McGovern Medical School at UTHealth, Houston, Texas 77030, ${ }^{2}$ MD Anderson Cancer Center UTHealth \\ Graduate School of Biomedical Sciences, Houston, Texas 77030, and ${ }^{3}$ Department of Neuroscience, Baylor College of Medicine, Houston, Texas \\ 77030
}

During sleep, neurons in the thalamic reticular nucleus (TRN) participate in distinct types of oscillatory activity. While the reciprocal synaptic circuits between TRN and sensory relay nuclei are known to underlie the generation of sleep spindles, the mechanisms regulating slow $(<1 \mathrm{~Hz})$ forms of thalamic oscillations are not well understood. Under in vitro conditions, TRN neurons can generate slow oscillations in a cell-intrinsic manner, with postsynaptic Group 1 metabotropic glutamate receptor activation triggering long-lasting plateau potentials thought to be mediated by both T-type $\mathrm{Ca}^{2+} \mathrm{currents}$ and $\mathrm{Ca}^{2+}$-activated nonselective cation currents $\left(\mathrm{I}_{\mathrm{CAN}}\right)$. However, the identity of $\mathrm{I}_{\mathrm{CAN}}$ and the possible contribution of thalamic circuits to slow rhythmic activity remain unclear. Using thalamic slices derived from adult mice of either sex, we recorded slow forms of rhythmic activity in TRN neurons, which were driven by fast glutamatergic thalamoreticular inputs but did not require postsynaptic Group 1 metabotropic glutamate receptor activation. For a significant fraction of TRN neurons, synaptic inputs or brief depolarizing current steps led to long-lasting plateau potentials and persistent firing (PF), and in turn, resulted in sustained synaptic inhibition in postsynaptic relay neurons of the ventrobasal thalamus (VB). Pharmacological approaches indicated that plateau potentials were triggered by $\mathrm{Ca}^{2+}$ influx through T-type $\mathrm{Ca}^{2+}$ channels and mediated by $\mathrm{Ca}^{2+}-$ and voltage-dependent transient receptor potential melastatin 4 (TRPM4) channels. Together, our results suggest that thalamic circuits can generate slow oscillatory activity, mediated by an interplay of TRN-VB synaptic circuits that generate rhythmicity and TRN cell-intrinsic mechanisms that control PF and oscillation frequency.

Key words: oscillation; persistent activity; T-type; thalamic reticular nucleus; thalamocortical; TRPM4

Significance Statement

Slow forms of thalamocortical rhythmic activity are thought to be essential for memory consolidation during sleep and the efficient removal of potentially toxic metabolites. In vivo, thalamic slow oscillations are regulated by strong bidirectional synaptic pathways linking neocortex and thalamus. Therefore, in vitro studies in the isolated thalamus offer important insights about the ability of individual neurons and local circuits to generate different forms of rhythmic activity. We found that circuits formed by GABAergic neurons in the thalamic reticular nucleus and glutamatergic relay neurons in the ventrobasal thalamus generated slow oscillatory activity, which was accompanied by persistent firing in thalamic reticular nucleus neurons. Our results identify both cell-intrinsic and synaptic mechanisms that mediate slow forms of rhythmic activity in thalamic circuits.

\footnotetext{
Received Feb. 10, 2020; revised Apr. 13, 2020; accepted May 11, 2020.

Author contributions: J.J.0., F.S., J.C., and M.B. designed research; J.J.0. and F.S. performed research; J.J.0.,

F.S., and M.B. analyzed data; J.J.O. and M.B. wrote the paper; F.S. and J.C. edited the paper.

The authors declare no competing financial interests.

This work was supported by the Harry S. and Isabel C. Cameron Foundation to J.J.0., the Neurodegeneration Consortium and the Belfer Family Foundation to J.C. and M.B., National Institutes of Health NS085171 and NS086965 to J.C., and National Institutes of Health NS077989 to M.B. We thank Michael Zhu and Oleh Pochynyuk for donating mouse models, John Magnotti for statistical advice, and Rajan Dasgupta and Fabricio Do Monte for helpful discussions.

Correspondence should be addressed to Michael Beierlein at michael.beierlein@uth.tmc.edu. https://doi.org/10.1523/JNEUROSCI.0324-20.2020

Copyright $\odot 2020$ the authors
}

\section{Introduction}

Slow $(<1 \mathrm{~Hz})$ rhythmic activity in the thalamocortical system is a defining feature of natural sleep and is thought to be essential for the grouping of higher-frequency activity, such as sleep spindles (Beenhakker and Huguenard, 2009; Lüthi, 2014), network plasticity and memory consolidation (Steriade and Timofeev, 2003; Diekelmann and Born, 2010), and homeostatic processes, including the clearance of metabolites (Varga et al., 2016). On a cellular level, slow oscillations are characterized by rapid transitions between periods of sustained depolarizations and persistent activity (Up states) and quiescence (Down states), in both neocortex (Steriade et al., 1993b; Sanchez-Vives and McCormick, 
2000) and thalamus (Steriade et al., 1993a; Crunelli and Hughes, 2010). It is well established that neocortex plays an important role in the generation of slow oscillations (Steriade et al., 1993b; Sanchez-Vives and McCormick, 2000; Neske, 2016), with cortical activity leading to the recruitment of thalamic targets via extensive corticothalamic projections (Steriade et al., 1993a; Stroh et al., 2013). However, accumulating evidence shows that, rather than being passively entrained by cortical afferents, thalamus can generate distinct types of rhythmic activity, which in turn shape cortical activity patterns (Rigas and Castro-Alamancos, 2007; Halassa et al., 2011; David et al., 2013; Lemieux et al., 2014; Fernandez et al., 2018). Thus, rhythms in the thalamocortical system might result from the interplay of multiple distinct oscillators (Crunelli and Hughes, 2010). While there is strong consensus on the mechanisms that underlie slow oscillations in neocortex (Crunelli and Hughes, 2010; Neske, 2016), it is important to gain a better understanding of how thalamic neurons and circuits generate slow forms of rhythmic activity.

In vitro studies in the isolated thalamus have shown that neurons in the thalamic reticular nucleus (TRN) (Blethyn et al., 2006) and in thalamic relay nuclei (Hughes et al., 2002) can act as cellular pacemakers of slow rhythms, under conditions of sustained activation of postsynaptic Group 1 metabotropic glutamate receptors (mGluRs) by either exogenous agonists or highfrequency corticothalamic activity. This results in an increase in excitability, due to the closure of a $\mathrm{K}^{+}$leak conductance, enabling low threshold $\mathrm{Ca}^{2+}$ currents $\left(\mathrm{I}_{\mathrm{T}}\right)$ and $\mathrm{Ca}^{2+}$-activated nonselective cation currents $\left(\mathrm{I}_{\mathrm{CAN}}\right)$ to generate long-lasting and rhythmic plateau potentials, which in TRN neurons lead to persistent action potential activity (Blethyn et al., 2006). However, the precise role of $\mathrm{I}_{\mathrm{T}}$ and the molecular mechanisms mediating $\mathrm{I}_{\text {CAN }}$ is not known (Zylberberg and Strowbridge, 2017; Crunelli et al., 2018). Moreover, these findings do not directly address a potential role of intrathalamic networks. TRN and relay neurons form powerful reciprocal connections (Gentet and Ulrich, 2003; Pinault, 2004; Pita-Almenar et al., 2014), which underlie the generation of sleep spindles (Beenhakker and Huguenard, 2009), but whether these circuits can also generate slower forms of oscillatory activity is not known.

Here we addressed these questions by performing recordings in horizontal slices of somatosensory thalamus of adult mice. Surprisingly, we observed highly robust slow oscillatory activity, which was driven by fast synaptic transmission but did not require $\mathrm{mGluR}$ activation. We found that a significant number of TRN neurons displayed synaptically evoked persistent firing (PF), which could also be evoked by brief depolarizing current steps in the absence of synaptic signaling. PF was triggered by $\mathrm{Ca}^{2+}$ influx through T-type $\mathrm{Ca}^{2+}$ channels and generated by long-lasting plateau potentials mediated by TRPM4 conductances. Our findings highlight how intrinsic properties of TRN neurons and intrathalamic synaptic circuits interact to generate slow thalamic oscillatory activity.

\section{Materials and Methods}

Animals. We used C57BL6/J mice (JAX Laboratories, stock \#000664) unless specified otherwise. For some experiments, we used TRPC1,4,5,6 general quadruple KO mice (Sachdeva et al., 2018) kindly provided by Michael Zhu (McGovern Medical School at UTHealth) or TRPC3 general KO mice (Hartmann et al., 2008) kindly provided by Oleh Pochynyuk (McGovern Medical School at UTHealth). To optogenetically activate cholinergic inputs to TRN, we used bacterial artificial chromosome (BAC)-transgenic mice expressing channelrhodopsin (ChR2) under the control of the ChAT promoter (ChAT-ChR2-EYFP; JAX
Laboratories, stock \#014546) (Zhao et al., 2011). All animals used in this study were treated following procedures in accordance with National Institutes of Health guidelines and approved by the UTHealth Animal Welfare Committee.

Slice preparation. Brain slices derived from adult animals (P90-P120) were prepared as described previously (Ting et al., 2014). Briefly, mice of either sex were anesthetized using isoflurane and perfused using an icecold N-methyl-D-glutamine (NMDG)-based solution saturated with 95\% $\mathrm{O}_{2} / 5 \% \mathrm{CO}_{2}$ consisting of the following (in $\mathrm{mM}$ ): $92 \mathrm{NMDG}, 2.5 \mathrm{KCl}, 1.25$ $\mathrm{NaH}_{2} \mathrm{PO}_{4}, 10 \mathrm{MgSO}_{4}, 0.5 \mathrm{CaCl}_{2}, 30 \mathrm{NaHCO}_{3}, 20$ glucose, 20 HEPES, 2 thiouera, $5 \mathrm{Na}$-ascorbate, and $3 \mathrm{Na}$-pyruvate. Brains were removed, and horizontal slices $(300 \mu \mathrm{m})$ were cut in ice-cold NMDG-based solution using a VT1200 S vibratome (Leica Microsystems). Slices were then held in NMDG-based solution maintained at $35^{\circ} \mathrm{C}$ for $\sim 12$ min before being transferred to a modified ACSF held at room temperature, consisting of the following (in mM): $92 \mathrm{NaCl}, 2.5 \mathrm{KCl}, 1.25 \mathrm{NaH}_{2} \mathrm{PO}_{4}, 2 \mathrm{MgSO}_{4}, 2$ $\mathrm{CaCl}_{2}, 30 \mathrm{NaHCO}_{3}, 25$ glucose, 20 HEPES, 2 thiouera, $5 \mathrm{Na}$-ascorbate, and 3 Na-pyruvate. Slices from younger animals (P13-P38) were prepared as described previously (Agmon and Connors, 1991). Briefly, mice were anesthetized using isoflurane and then decapitated. Slices were cut in icecold cutting solution saturated with $95 \% \mathrm{O}_{2} / 5 \% \mathrm{CO}_{2}$ consisting of the following (in mM): 213.4 sucrose, $2.5 \mathrm{KCl}, 1.25 \mathrm{NaH}_{2} \mathrm{PO}_{4}, 10 \mathrm{MgSO}_{4}, 0.5$ $\mathrm{CaCl}_{2}, 26 \mathrm{NaHCO}_{3}$, and 11 glucose. Slices were then transferred to ACSF consisting of the following (in mM): $126 \mathrm{NaCl}, 2.5 \mathrm{KCl}, 1.25 \mathrm{NaH}_{2} \mathrm{PO}_{4}, 2$ $\mathrm{MgCl}_{2}, 2 \mathrm{CaCl}_{2}, 26 \mathrm{NaHCO}_{3}$, and 10 glucose, incubated at $35^{\circ} \mathrm{C}$ for $20 \mathrm{~min}$, and then held at room temperature until used for experiments.

Electrophysiological recordings. Recordings were performed in a chamber perfused with ACSF held at $32^{\circ} \mathrm{C}-34^{\circ} \mathrm{C}$ using a TC-324B inline heater (Warner Instruments). Cells were visualized via infrared differential interference contrast under an Olympus BX51WI microscope equipped with a Dage-MTI IR-1000 camera. Whole-cell recordings were obtained using glass pipettes with a tip resistance of 3-5 $\mathrm{M} \Omega$. For current-clamp recordings in TRN, we used a potassium-based internal solution consisting of the following (in $\mathrm{mM}$ ): $133 \mathrm{~K}$-gluconate, $1 \mathrm{KCl}, 2$ $\mathrm{MgCl}_{2}, 0.16 \mathrm{CaCl}_{2}, 10$ HEPES, 0.5 EGTA, $2 \mathrm{Mg}$-ATP, and $0.4 \mathrm{Na}$-GTP (adjusted to $290 \mathrm{mOsm}$ and $\mathrm{pH}$ 7.3). For voltage-clamp recordings of inhibitory postsynaptic currents in neurons of the ventrobasal thalamus (VB), recording pipettes were filled with a cesium-based internal solution consisting of the following (in mM): $120 \mathrm{CsMeSO}_{3}, 1 \mathrm{MgCl}_{2}, 1$ $\mathrm{CaCl}_{2}, 10 \mathrm{CsCl}, 10$ HEPES, 3 QX-314, 11 EGTA, $2 \mathrm{Mg}$-ATP, and $0.3 \mathrm{Na}-$ GTP (adjusted to $295 \mathrm{mOsm}$ and $\mathrm{pH}$ 7.3). For loose-patch recordings of TRN neuronal firing, glass pipettes (3-5 M 2 ) were filled with ACSF, and recordings were obtained in voltage-clamp mode, at seal resistances of 50-200 M $\Omega$. To minimize any influence on the cell membrane potential, the holding voltage was adjusted continually to maintain a holding current near $0 \mathrm{pA}$ (Perkins, 2006). In experiments probing TRN oscillatory activity, glutamine $(0.3 \mathrm{~mm})$ was added to the ACSF to prevent a rundown of network activity (Bryant et al., 2009; Pita-Almenar et al., 2014). For experiments examining the mechanisms of PF, the bath contained NBQX. In some experiments, we replaced extracellular $\mathrm{NaCl}$ with equimolar NMDG and used an internal solution consisting of the following (in $\mathrm{mM}$ ): $133 \mathrm{~K}$-gluconate, $1 \mathrm{KCl}, 4 \mathrm{NaCl}, 2 \mathrm{MgCl}_{2}, 0.16 \mathrm{CaCl}_{2}, 10$ HEPES, 0.5 EGTA, $2 \mathrm{Mg}$-ATP, and 0.4 Na-GTP (adjusted to $290 \mathrm{mOsm}$ and $\mathrm{pH}$ 7.3). For optogenetic activation of cholinergic afferents, we used $1 \mathrm{~ms}$ pulses of blue light generated by an LED light source (UHP-T-450EP, Prizmatix) delivered through a $60 \times, 0.9$ NA water-immersion objective (Olympus) and centered locally in the TRN.

NBQX, apamin, nimodipine, TTX, 2-aminoethoxydiphenylborane (2APB), flufenamic acid (FFA), 9-phenthranol, glibenclamide, 4-chloro-2[[2-(2-chlorophenoxy)acetyl]amino]benzoic acid (CBA), JNJ 16259685, MTEP hydrochloride, and atropine were obtained from R\&D Systems. $\omega$-Conotoxin MVII and TTA-P2 were obtained from Alomone Labs. All other chemicals were obtained from Sigma Millipore.

Data acquisition. Recordings were made using a Multiclamp 700B amplifier (Molecular Devices), filtered at $3-10 \mathrm{kHz}$, and digitized at $20 \mathrm{kHz}$ with a 16-bit analog-to-digital converter (Digidata 1440A; Molecular Devices). Data were acquired using Clampex 10.3 software (Molecular Devices) and analyzed using custom macros written in IGOR Pro (Wavemetrics). 
Experimental design and statistical analysis. TRN neuronal firing evoked by brief $(25 \mathrm{~ms})$ current steps was classified into two groups, bursting and PF, based on the duration of the evoked membrane depolarization measured at half-amplitude (see Results). Post hoc $k$ means cluster analysis confirmed that classification into two clusters explained the largest amount of variance. We used a depolarization duration of $200 \mathrm{~ms}$ to distinguish between bursting and PF. Because of rundown of PF in whole-cell mode, data acquisition in the TRN was limited to $3 \mathrm{~min}$ following establishment of whole-cell configuration. Pharmacological experiments examining the mechanisms underlying PF were conducted by performing recordings in the presence of a given antagonist under study, and comparing results with recordings performed under control conditions. All data in a given group were collected from slices derived from a minimum of 2 animals and reported as mean \pm SEM. All statistical analyses were performed with Prism 7 software. To evaluate significant differences in the proportion of PF between different experimental groups, we performed a $\chi^{2}$ test, and report results in the following format: degrees of freedom in parentheses, followed by the $\chi^{2}$ value and $p$ value. To test for significant differences in the duration of evoked membrane depolarization between groups of neurons, we performed an unpaired $t$ test and report results as follows: degrees of freedom in parentheses, followed by $t$ value and $p$ value. Statistical significance was set at $p<0.05$ and adjusted for multiple statistical comparisons with a Bonferroni correction to correct for pairwise error and to reduce Type I error.

\section{Results}

Slow oscillatory activity and PF in thalamic networks

Following activation of postsynaptic Group I mGluRs, individual neurons in the TRN can generate slow oscillatory responses, reminiscent of thalamic activity during sleep (Blethyn et al., 2006). It remains unclear how thalamic synaptic networks contribute to slow oscillatory activity. To examine this issue, we performed experiments in horizontal thalamic slices derived from adult ( $>3$ month) mice. We and others have previously used extracellular or optogenetic synaptic stimulation to trigger transient $(<2$ s) forms of rhythmic thalamic activity in vitro (Huguenard and Prince, 1994; Pita-Almenar et al., 2014). Surprisingly, by performing loose-patch recordings from TRN neurons, we observed spontaneous and highly rhythmic patterns of action potential activity that could last several minutes $(n=47$ TRN neurons, $n=17$ slices). For 12 of 47 (26\%) of recordings, action potential activity was organized as rhythmic bursting (frequency: $1.9 \pm 0.1 \mathrm{~Hz}, n=12$; Fig. $1 A$ ). Interestingly, a second group of recordings (17 of $47,36 \%$ ) revealed rhythmic patterns of sustained action potential activity ( $>200 \mathrm{~ms}$ duration) we termed PF, characterized by an initial high-frequency burst, followed by a long-lasting train of action potentials (average duration: $964.9 \pm 256.4 \mathrm{~ms}$, average firing frequency: $175 \pm 23.4 \mathrm{~Hz}$, $n=17$; Fig. $1 B$ ). For neurons displaying rhythmic PF, oscillation frequency was $0.5 \pm 0.1 \mathrm{~Hz}(n=17)$, significantly lower compared with the oscillation frequency of cells showing burst firing $\left(t_{(28)}=6.5, p=10^{-16}\right.$; Fig. $\left.1 D\right)$. The remaining recordings $(n=18)$ showed more complex patterns of activity and included neurons that displayed both rhythmic PF and burst firing ( $n=4$; Fig. $1 C$ ). These data indicate that burst firing and PF are prominent firing modes in the TRN and are associated with oscillatory activity at distinct frequencies.

Relay neurons in the VB receive their sole inhibitory input from neurons in the TRN. Therefore, the patterns of synaptic inhibitory responses recorded in VB neurons should closely reflect rhythmic spike firing observed in TRN. To confirm this, we performed voltage-clamp recordings from VB neurons at a holding potential of $0 \mathrm{mV}$ to isolate IPSCs. In $76 \%(n=22$ of 29$)$ of all VB
A

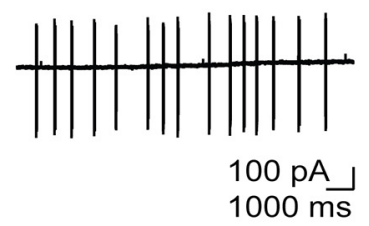

B

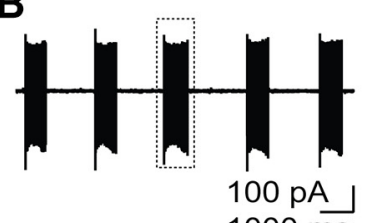

$1000 \mathrm{~ms}$

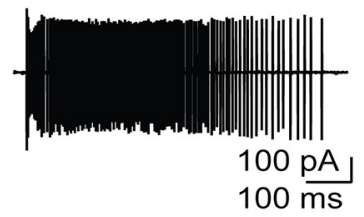

C
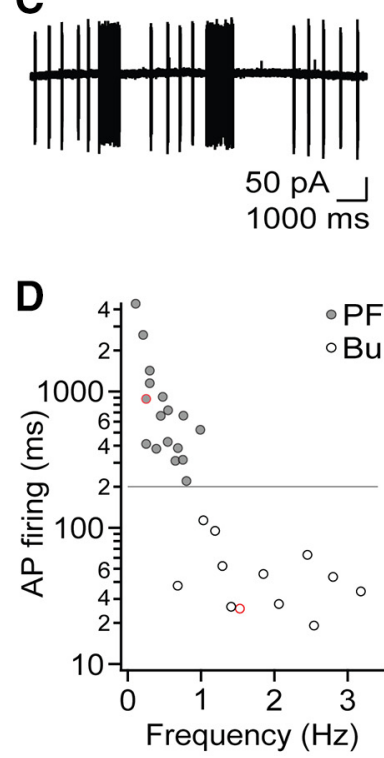

$\mathbf{E}$

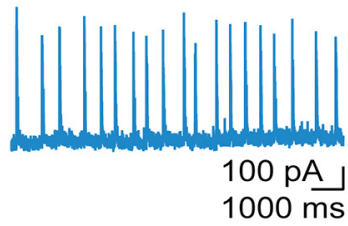

$\mathbf{F}$

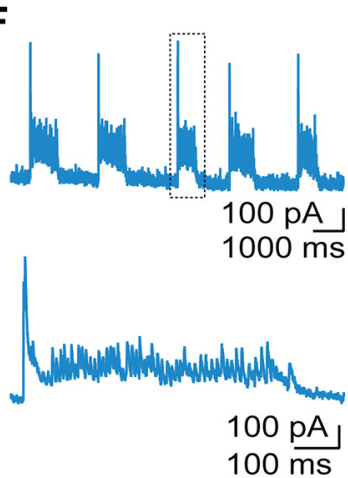

G

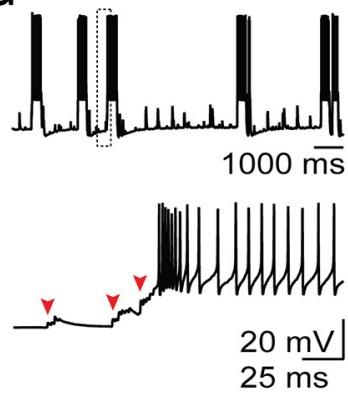

H

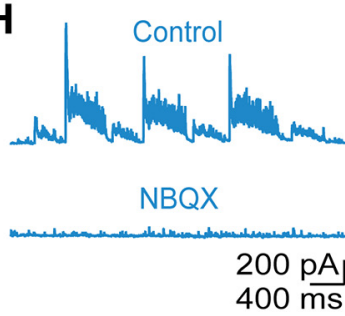

Figure 1. Rhythmic activity in thalamic networks. $\boldsymbol{A}$, Loose-patch recording from TRN neuron showing rhythmic burst firing. $\boldsymbol{B}$, Top, TRN neuron showing rhythmic PF. Bottom, Closeup highlighting an individual barrage of PF. C, TRN neuron showing rhythmic activity consisting of both burst firing and PF. $D$, Summary data $(n=29)$ plotting the average duration of TRN firing as a function of oscillation frequency, for neurons with either burst firing or PF. Red data points represent cells shown in $\boldsymbol{A}$ and $\boldsymbol{B}$. Dashed line indicates criterion separating between rhythmic bursting and PF. $\boldsymbol{E}$, Voltage-clamp recording from VB neuron held at $0 \mathrm{mV}$ displaying rhythmic bursts of IPSCS. $\boldsymbol{F}$, Top, Recording from VB neuron displaying rhythmic barrages of IPSCs. Bottom, Closeup shows an individual barrage of IPSCs. G, Top, Current-clamp recording from TRN neuron, showing PF during network activity. Bottom, Closeup shows that bursts of EPSPs (marked by red arrows) trigger PF. $\boldsymbol{H}$, Representative recording of rhythmic barrages of IPSCS in VB neuron, under control conditions and following bath application of NBQX (10 $\mu \mathrm{m})$. Similar data were obtained from four other VB neurons.

neurons that showed oscillatory synaptic activity, we recorded synaptic responses organized as long-lasting high-frequency IPSC barrages (duration: $620.1 \pm 54.3 \mathrm{~ms}, n=32$; Fig. $1 F$ ), which occurred rhythmically over several minutes $(0.5 \pm 0.1 \mathrm{~Hz}, n=$ 32). A smaller fraction of recordings showed rhythmic IPSC bursts $(n=4$; Fig. $1 E)$. Thus, relay neurons are the target of persistent inhibition during slow oscillatory activity, likely mediated by TRN neurons with PF. 
Postsynaptic mGluR activation by exogenous agonists or high-frequency stimulation of glutamatergic afferents can lead to slow oscillatory activity in TRN neurons, even in the absence of fast synaptic signaling (Blethyn et al., 2006). In contrast, by performing whole-cell recordings in TRN, we found that rhythmic patterns of PF did not occur spontaneously but instead were evoked by brief bursts of thalamoreticular EPSPs (Fig. 1G). Furthermore, rhythmic IPSCs recorded in VB cells were fully blocked by bath application of NBQX $(n=5$; Fig. $1 H$ ), suggesting that, similar to spindlelike activity (Huguenard and McCormick, 2007), slow oscillatory activity relied on a network of interconnected TRN and relay neurons, at least under our experimental conditions.

Anatomic and functional studies have shown considerable axonal divergence for TRN to VB projections, resulting in highly overlapping TRN afferents to neighboring VB neurons (Pinault, 2004; Pita-Almenar et al., 2014). In agreement, the timing and duration of oscillatory IPSC barrages were highly synchronous for local VB neuronal pairs $(<50 \mu \mathrm{m}$ somatic distance $)$ recorded simultaneously (Fig. 2A). Synchrony was maintained for individual IPSCs throughout the entire barrage, suggesting that the large majority of IPSCs were spike-mediated, without a detectable contribution of asynchronous GABA release (Hefft and Jonas, 2005).

We found that the majority of VB recordings showed oscillatory IPSC events with little variability of the initial IPSC amplitude and event duration (Fig. 1E,F), consistent with a single presynaptic TRN neuron. However, for a number of recordings, we observed either two ( $n=10 \mathrm{VB}$ cells; Figs. $1 \mathrm{H}, 2 \mathrm{~B}$, $C)$ or three ( $n=4 \mathrm{VB}$ cells; data not shown) different types of rhythmic IPSC events, with each type characterized by a distinct initial IPSC amplitude and event duration, suggesting convergent inputs from two or three presynaptic TRN neurons, respectively. For recordings with two types of events, event duration suggested convergent input by TRN cells that either both displayed PF $(n=6$; Fig. $2 C)$ or PF and bursting $(n=4$; Fig. $2 B)$. Importantly, IPSC events evoked by different presynaptic TRN neurons displayed clear rhythmicity but never occurred synchronously. These data confirm our previous findings derived in thalamic slices of less mature animals (Pita-Almenar et al., 2014) and suggest that local thalamic circuits can mediate ongoing oscillatory activity in the absence of widespread synchrony.

\section{Brief depolarizations trigger PF in TRN neurons}

So far, our data indicate that a significant fraction of TRN neurons shows PF during network activity. To better characterize the properties and underlying mechanisms of PF, we performed whole-cell recordings and blocked network activity by adding NBQX $(10 \mu \mathrm{M})$ to the bath solution. Neurons were held at a membrane potential of $-75 \mathrm{mV}$ unless stated otherwise, and action potentials were evoked using brief depolarizing current steps ( $25 \mathrm{~ms}, 400 \mathrm{pA})$. Such stimuli led to bursts of action potentials (average number of spikes: $8.1 \pm 0.2, n=74$ ) in $67 \%$ of neurons recorded (Fig. 3A). For the remaining neurons (37 of 111,
$33 \%$ ) we observed sustained action potential activity (average number of spikes: $72.2 \pm 9.8$, firing frequency: $99.1 \pm 7.5 \mathrm{~Hz}$, $n=37$ ), closely resembling PF observed during network activity. PF was mediated by long-lasting plateau potentials (amplitude from rest: $29.3 \pm 0.8 \mathrm{mV}$, plateau duration: $807.1 \pm 41.7 \mathrm{~ms}$, $n=37$; Fig. $3 A, B)$ that terminated in a stepwise manner. Using the duration of the current-step-evoked membrane depolarization, we performed $k$ means cluster analysis, confirming that TRN firing patterns can be most readily classified into two distinct groups, bursting and PF, with the latter group displaying membrane depolarizations of $>$ ms duration. Neurons with current-step-evoked PF were not restricted to a specific TRN subregion and were localized along the entire thickness of the TRN shell (not shown). We found that PF remained stable for several minutes but then decayed over time, regardless of composition of the internal solution (Fig. 3C). This might partly explain why studies using whole-cell methods have not reported PF in adult TRN neurons (e.g., Clemente-Perez et al., 2017), while at least one study using sharp electrode recordings described PF in a subset of neurons of the cat perigeniculate nucleus (U. Kim and McCormick, 1998). For the remainder of this study, we limited data acquisition to the first $3 \mathrm{~min}$ in whole-cell mode.

\section{PF occurs late during development and is controlled by SK conductances}

Previous work characterizing TRN firing patterns in slices derived from younger $(<\mathrm{P} 30)$ animals has not reported PF (Lee 
A
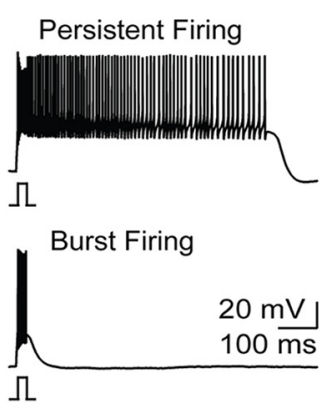

D
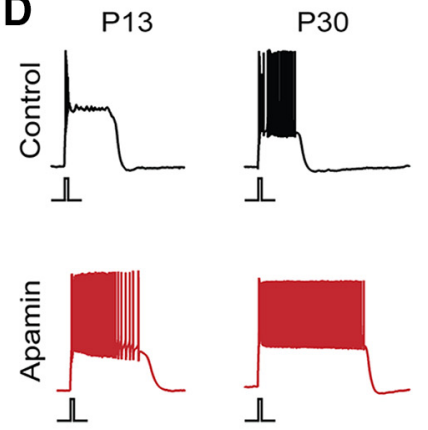

$\mathbf{F}$

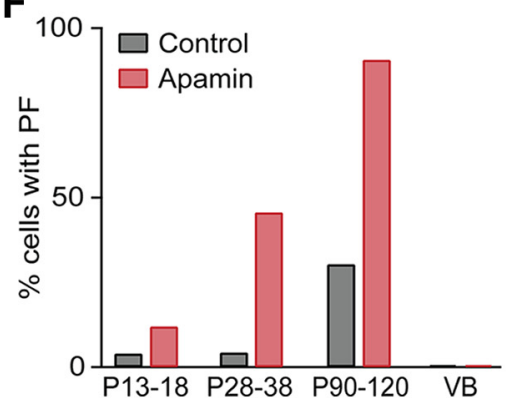

B

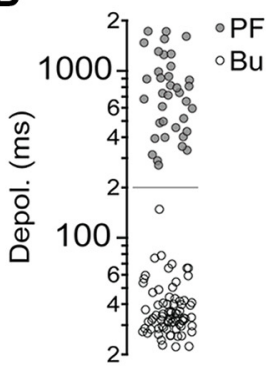

P98
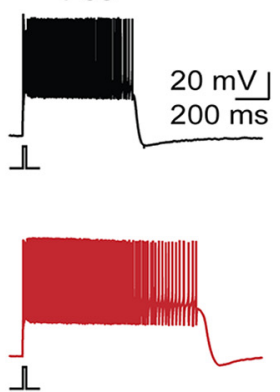

G

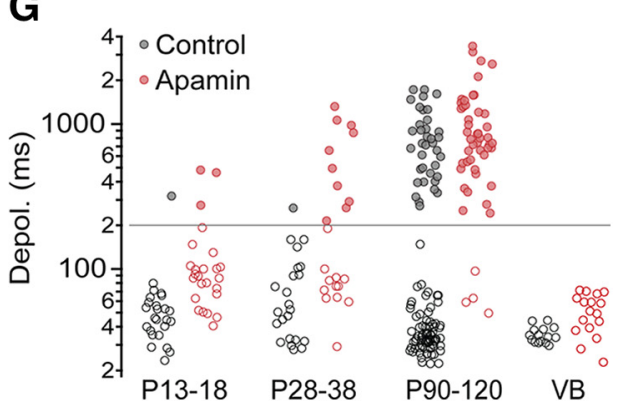

Figure 3. PF occurs late in development and regulated by SK conductances. $A$, Brief depolarizing current steps $(25 \mathrm{~ms}$, $400 \mathrm{pA}, \mathrm{RMP}=-75 \mathrm{mV}$ ) lead to two distinct firing patterns: PF (top) or burst firing (Bu, bottom). $B$, Summary data ( $n=111$ neurons) showing bimodal distribution of current-step-evoked membrane depolarization durations. Gray line indicates criterion separating PF and Bu. C, Raster plot of AP activity in representative TRN neuron showing rundown of PF. D, Representative recordings of TRN neurons with PF at three developmental stages, in control (black) and in the presence of apamin (500 nM, red). $\boldsymbol{E}$, Representative recordings of VB cells, in control (black) and in the presence of apamin (red) show lack of PF in both conditions. $\boldsymbol{F}$, Summary data showing incidence of PF in TRN across development (P13-P18: $n=24$ in control, $n=25$ in apamin; P28-P38: $n=23$ in control, $n=22$ in apamin; P90-P120: $n=111$ in control, $n=50$ in apamin) and in VB ( $n=15$ in control, $n=16$ in apamin). $\boldsymbol{G}$, For the same cells as in $\boldsymbol{F}$, summary data quantifying membrane depolarization duration across development, in control conditions and in apamin.

et al., 2007), indicating that PF might be developmentally regulated. To examine this possibility, we conducted additional recordings in slices prepared from mice aged P13-P18 and P28P38. Compared with adult mice, only 1 of 24 (4\%) of cells at P13-P18 and 1 of 23 (4\%) of cells at P28-P38 displayed PF (Fig. $3 D-F$ ), indicating that $\mathrm{PF}$ is prominent only in fully mature animals.

The generation of plateau potentials that underlie PF is likely to be tightly regulated by $\mathrm{K}^{+}$conductances, including small-conductance $\mathrm{Ca}^{2+}$-activated $\mathrm{K}^{+}$channels (SK). To examine this possibility, we performed recordings in the presence of the SK channel blocker apamin (100 nM). Under these conditions, a much larger fraction of TRN cells in adult animals showed PF $\left(92 \%, n=46\right.$ of $50, \chi_{(1)}^{2}=47.5, p=10^{-16}$; Fig. $\left.3 D-F\right)$. Thus, excitatory conductances responsible for PF are widely expressed in the adult TRN but appear to be strongly controlled by SK conductances. Given the role of SK channels in regulating PF in the adult, the developmental increase in PF we observed might be solely mediated by a progressive decrease of SK expression. However, we found that, even in the presence of apamin, the incidence of PF remained very low early in development and dramatically increased with animal age (P13-P18: $12 \%, n=25$; P28-P38: 41\%, $n=24$; P90-P120: 92\%; Fig. 3D-F), suggesting a developmental upregulation of excitatory mechanisms that underlie PF. Finally, we examined whether neurons in the VB displayed plateau potentials in control conditions or in the presence of apamin. In contrast to TRN, PF was completely absent from VB under both conditions (Fig. 3E,G). Thus, the mechanisms underlying PF do not appear to be uniformly expressed in all thalamic nuclei.

\section{Metabotropic glutamate receptor activation is not necessary for $\mathrm{PF}$}

Previous work has highlighted a critical role of postsynaptic Group 1 mGluR activation in enabling intrinsic oscillations and Up states in TRN neurons (Blethyn et al., 2006). While PF under our experimental conditions did not require exogenous or synaptic mGluR I activation, it is possible that mGluRs were tonically activated by ambient glutamate (Crabtree et al., 2013) or in a ligand-independent manner (Sun et al., 2016). To examine this possibility, we probed TRN firing in the presence of the noncompetitive mGluR1 antagonist JNJ 16259685 (JNJ) and the noncompetitive mGluR5 antagonist MTEP. Block of Group 1 mGluRs did not significantly change the incidence of PF (control: 33\%, $n=111$; JNJ+MTEP: $48 \%, n=27 ; \quad \chi_{(1)}^{2}=1.7, p=$ $0.19)$ or the plateau potential duration for cells with PF (control: 807.1 $\pm 41.7 \mathrm{~ms}$; JNJ+MTEP: $599.8 \pm 64.3 \mathrm{~ms} ; t_{(46)}=1.85$, $p=0.071$; Fig. $4 A, B)$. These data suggest that, under our experimental conditions, Group I mGluR activation is not essential for PF.

\section{Activation of T-type $\mathrm{Ca}^{2+}$ channels is required for PF}

Next, we examined whether PF is voltage-dependent, by evoking action potential activity from two distinct holding potentials. TRN cells held initially at $-60 \mathrm{mV}$ never displayed PF or plateau potentials ( 0 of 15 cells; Fig. $4 C, D$ ). However, when the holding potential was adjusted to $-75 \mathrm{mV}, 8$ of 15 neurons generated $\mathrm{PF}$ $\left(\chi_{(1)}^{2}=1.7, p=0.0013\right)$, suggesting that the underlying mechanisms of $\mathrm{PF}$ are voltage-dependent.

To further isolate the mechanisms responsible for PF, we used a pharmacological approach. Because of the washout of PF in whole-cell mode, it was not possible to quantify changes in PF before and following bath application of antagonists for a given neuron. Therefore, we performed all recordings in the presence of a given antagonist and made comparisons with neurons recorded under control conditions (see Materials and Methods). 
A

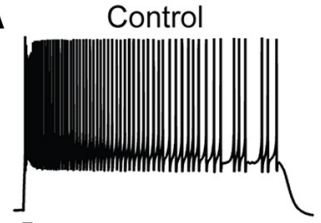

$几 \quad J N J+M T E P$

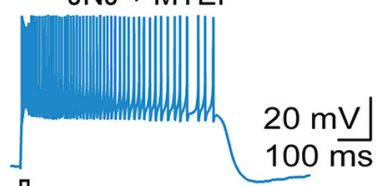

$几$

B
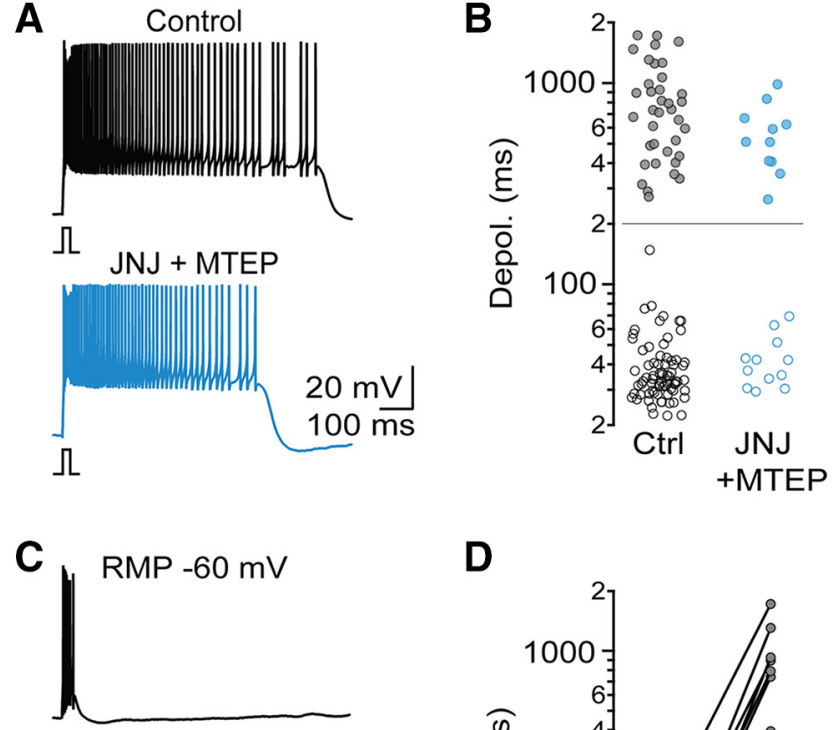

$\Omega$

RMP $-75 \mathrm{mV}$

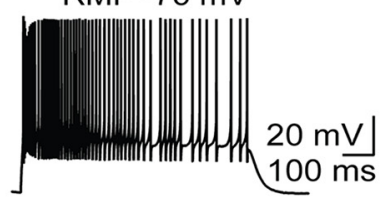

$几$
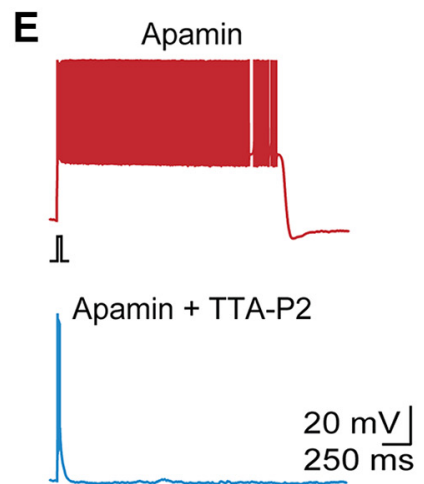

$\llbracket$

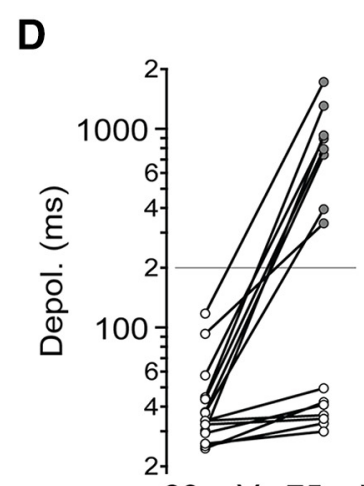

$-60 m \vee-75 m \vee$

$\mathbf{F}$

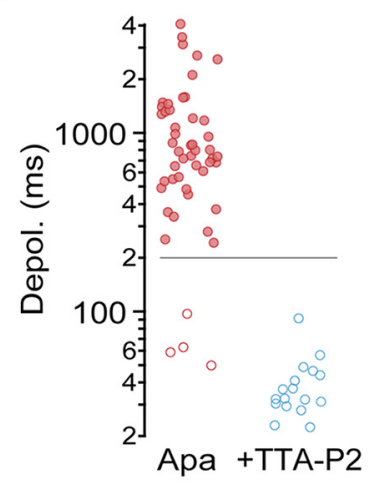

Figure 4. T-type $\mathrm{Ca}^{2+}$ channels, but not mGluRs, are required for PF. $A$, Representative recordings of PF from two different TRN neurons, in control conditions and in the presence of the mGluR1 antagonist JNJ $16259685(1 \mu \mathrm{M})$ and the mGluR5 antagonist MTEP $(10 \mu \mathrm{M})$. $B$, Summary data quantifying duration of evoked membrane depolarization in control $(n=111)$ and in the presence of mGluR $1 / 5$ antagonists $(n=23)$. C, Representative recording from neuron with PF, initially held at a holding potential of $-60 \mathrm{mV}$ and then at $-75 \mathrm{mV}$. D. Summary data quantifying evoked depolarization duration as a function of holding potential ( $n=15$ TRN neurons). $\boldsymbol{E}$, Representative recordings in the presence of apamin and in the presence of apamin and the T-type $\mathrm{Ca}^{2+}$ channel antagonist TTA-P2 $(1 \mu \mathrm{M}) . \boldsymbol{F}$, Summary data quantifying evoked depolarization duration ( $n=50$ in apamin, $n=17$ in apa$\min +$ TTA-P2).

To limit the number of recordings required for meaningful statistical comparisons, we performed the following experiments in the presence of apamin, which, as described above, results in PF in $92 \%$ of neurons (Fig. $3 E, F$ ).

Previous studies have indicated that, in thalamic neurons, Ttype $\mathrm{Ca}^{2+}$ channels are critical for the generation of mGluR-dependent Up states (Hughes et al., 2002; Blethyn et al., 2006). The voltage dependence of PF we observed appears to be consistent with these results. To confirm the involvement of T-type $\mathrm{Ca}^{2+}$

A
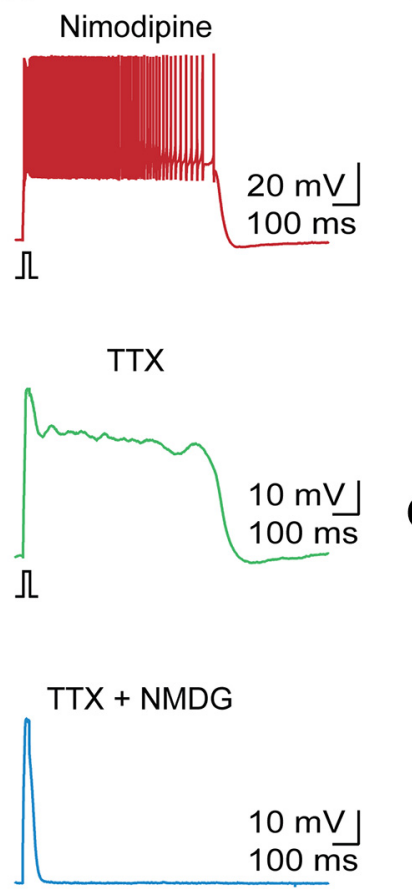

B
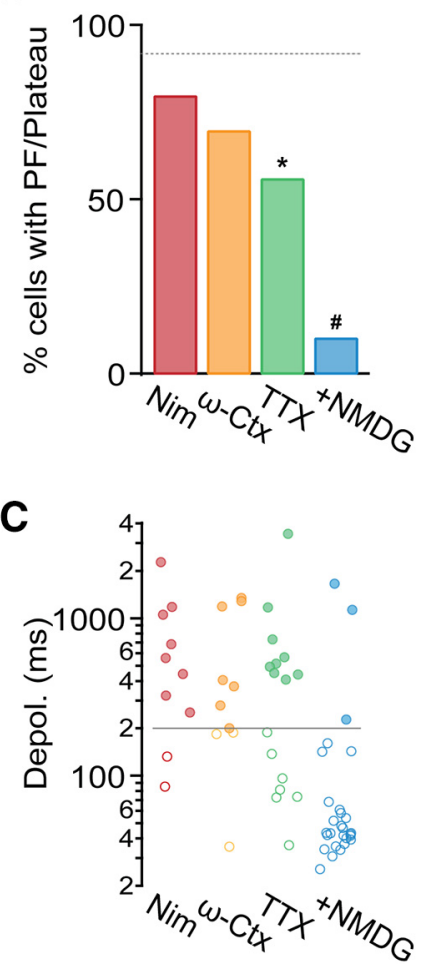

Figure 5. A TTX-insensitive sodium current generates plateau potential. All recordings were performed in the presence of apamin. $\boldsymbol{A}$, Representative TRN recordings in the presence of the L-type $\mathrm{Ca}^{2+}$ channel antagonist nimodipine (20 $\mu \mathrm{m}$, top), in TTX (500 nм, middle), and in the presence of TTX and NMDG replacing extracellular $\mathrm{Na}^{+}$(bottom). $\boldsymbol{B}$, Summary data showing incidence of PF in the presence of nimodipine (Nim, $n=10)$, the P/Q- and $\mathrm{N}$ type $\mathrm{Ca}^{2+}$ channel antagonist $\omega$-conotoxin MVIIC ( $\omega$-Ctx, $\left.1 \mu \mathrm{m}, n=10\right)$, TTX ( $\left.n=16\right)$, and TTX and NMDG $(n=28)$. Dashed line indicates incidence of PF in apamin. C, Summary data from the same cells as in $\boldsymbol{B}$, quantifying evoked depolarization duration in each condition. Gray solid line indicates criterion for PF. ${ }^{*} p<0.05$ compared with recordings in apamin group. ${ }^{\#} p<0.05$ compared with recordings in TTX.

channels in generating PF, we performed recordings in the presence of the specific antagonist TTA-P2 $(1 \mu \mathrm{M})$. Under these conditions, PF was completely eliminated (apamin: $92 \%$, apamin + TTA-P2: $0 \%, n=17, \chi_{(1)}^{2}=46.5, p=10^{-20}$; Fig. $\left.4 E, F\right)$. Thus, Ttype $\mathrm{Ca}^{2+}$ channels are required for the generation of PF.

\section{The plateau potential underlying PF is mediated by a sodium} current

It is possible that long-lasting plateau potentials in TRN neurons are entirely mediated by persistent T-type $\mathrm{Ca}^{2+}$ currents (Williams et al., 1997; Zylberberg and Strowbridge, 2017). While these channels show rapid inactivation following strong depolarization, their inactivation is not complete for smaller depolarizations near the resting membrane potential, resulting in a steady-state inward ("window") current. However, PF observed in the present study was accompanied by large membrane depolarizations that do not appear to be compatible with a significant role of Ttype $\mathrm{Ca}^{2+}$ channels. Therefore, we systematically examined the possible involvement of other voltage- or $\mathrm{Ca}^{2+}$-gated noninactivating conductances. We first tested the role of high-threshold $\mathrm{Ca}^{2+}$ channels (L, P/Q, and N). In the presence of the selective L-type antagonist nimodipine (Nim, $20 \mu \mathrm{M}$; Fig. 5A), the incidence of PF (apamin: 92\%, apamin + Nim: $80 \%, n=10$, $\chi_{(1)}^{2}=0.3, p=0.6$; Fig. $\left.5 B\right)$ and plateau potential duration for cells with PF (apamin: $1108.5 \pm 126.6 \mathrm{~ms}$, apamin + Nim: 
A
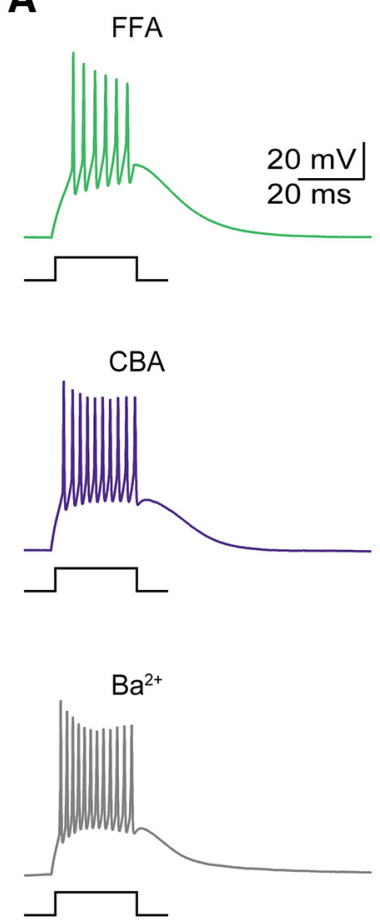

B

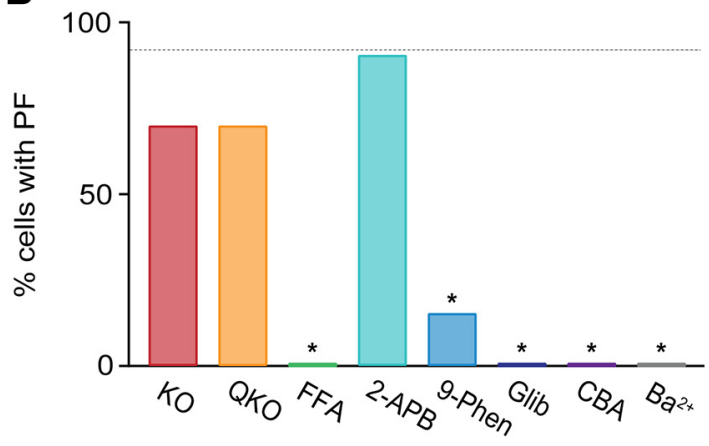

C

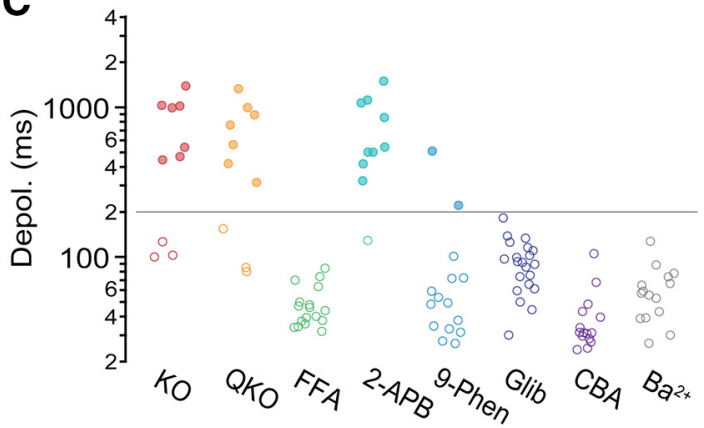

Figure 6. TRPM4 conductances mediate PF. All recordings were performed in the presence of apamin. $\boldsymbol{A}$, Representative recordings in control and in the presence of the nonselective TRP channel antagonist FFA (100 $\mu \mathrm{m}$, top), the TRPM4 antagonist CBA (50 $\mu \mathrm{m}$, middle), and in $2 \mathrm{~mm} \mathrm{BaCl} 2$ replacing extracellular $\mathrm{CaCl}_{2}$ (bottom). $\boldsymbol{B}$, Summary data showing incidence of PF in $\operatorname{TRPC3~KO~(~} n=10$ cells), QKO ( $n=10$ cells), FFA $(n=17)$, the nonselective TRP channel antagonist 2-APB $(50 \mu \mathrm{M}, n=10)$, the TRPM4/5 antagonists 9-phenthranol (9-Phen, $100 \mu \mathrm{M}, n=15)$, glibenclamide (Glib, $100 \mu \mathrm{M}, n=21), \mathrm{CBA}(n=15)$, and $\mathrm{Ba}^{2+}$ $(n=15)$. Gray dashed line indicates incidence of PF in apamin. $\boldsymbol{C}$, For the same cells as in $\boldsymbol{B}$, summary data quantifying the evoked depolarization duration. ${ }^{*} p<0.05$ compared with recordings in apamin.

$846.8 \pm 235 \mathrm{~ms}, t_{(48)}=0.9, p=0.38$; Fig. $5 C$ ) remained comparable to responses recorded in apamin. Similarly, incubating slices in the P/Q and N antagonist $\omega$-conotoxin MVIIC ( $\omega$-Ctx, $1 \mu \mathrm{M})$ did not lead to significant changes in the incidence of PF (apamin: $92 \%$, apamin $+\omega$-Ctx: $70 \%, n=10, \chi_{(1)}^{2}=1.4, p=0.23$; Fig. $5 B$ ), and plateau potential duration (apamin: $1108.5 \pm 126.6 \mathrm{~ms}$, apamin $+\omega$-Ctx: $726.7 \pm 196.2 \mathrm{~ms}, t_{(47)}=1.2, p=0.24$; Fig. $5 C$ ), suggesting that high-threshold $\mathrm{Ca}^{2+}$ channels do not play a critical role in $\mathrm{PF}$.

It is possible that plateau potentials are mediated by activation of a persistent $\mathrm{Na}^{+}$current $\left(\mathrm{I}_{\mathrm{NaP}}\right)$ as was suggested previously (U. Kim and McCormick, 1998; Fuentealba et al., 2005). We found that, in the presence of apamin and TTX (500 nM), fast action potential activity was completely blocked, revealing a plateau potential in 9 of 16 cells (amplitude: $30 \pm 1.2 \mathrm{mV}, n=16$; Fig. 5A), a smaller fraction compared with conditions in apamin (apamin: 92\%, apamin + TTX: 56\%, $\chi_{(1)}^{2}=10, p=0.002$; Fig. $5 B)$. Plateau potential duration remained comparable to control (apamin: $1108.5 \pm 126.6 \mathrm{~ms}$, apamin + TTX: $912.8 \pm 325.7 \mathrm{~ms}$, $t_{(49)}=0.7, p=0.5$; Fig. $5 C$ ). These data indicate that voltage-gated $\mathrm{Na}^{+}$currents facilitate plateau potential generation but are not strictly required for many TRN neurons.

Next, we examined whether $\mathrm{Na}^{+}$currents other than the ones carried by voltage-gated $\mathrm{Na}^{+}$channels are essential for plateau potentials, by substituting the majority of extracellular $\mathrm{Na}^{+}$with NMDG. We found that, in the presence of NMDG (together with apamin and TTX), the incidence of plateau potential generation was significantly reduced (apamin + TTX: 56\%, apamin + TTX + NMDG: $11 \%, n=28, \chi_{(1)}^{2}=10.6, p=0.001$; Fig. $\left.5 A-C\right)$, suggesting that $\mathrm{PF}$ is mediated at least in part by a TTX-insensitive $\mathrm{Na}^{+}$current.

\section{TRPM4 channels underlie PF in the TRN}

Our data thus far are consistent with a role of the $\mathrm{Ca}^{2+}$-activated nonselective cationic current $\left(\mathrm{I}_{\mathrm{CAN}}\right)$ in mediating plateau potentials. Transient receptor potential (TRP) channels have been previously proposed as molecular mechanisms mediating $\mathrm{I}_{\mathrm{CAN}}$ (Launay et al., 2002), with transient receptor potential canonical (TRPC) and melastatin (TRPM) channels as the most likely candidates. To examine the potential involvement of TRPC channels, we performed recordings in slices derived from global TRPC3 null mutant mice (TRPC3 KO) (Hartmann et al., 2008) and from global quadruple TRPC1,4,5,6 null mutant mice (QKO) (Tian and Zhu, 2018), in the presence of apamin. For both mouse lines, the incidence of PF (apamin: 92\%, TRPC3 KO: $70 \%, n=10, \chi_{(1)}^{2}=3.4, p=0.65$, QKO: $70 \%, n=10, \chi_{(1)}^{2}=3.4, p=0.65$; Fig. $6 B$ ) and plateau potential duration (apamin: $1108.5 \pm 126.6 \mathrm{~ms}$, TRPC3 KO: $841.1 \pm$ $136 \mathrm{~ms}, t_{(47)}=0.9, p=0.39$, QKO: $752.6 \pm$ $133.4 \mathrm{~ms}, t_{(47)}=1.1, p=0.27$; Fig. $6 C$ ) was comparable with our observations in WT animals, suggesting that at least 5 of the 7 TRPCs known to be expressed in the brain are not involved in mediating PF.

Next, we investigated a possible role of TRPM channels in mediating PF. TRPM2 has been shown to facilitate burst firing (Lee et al., 2013), whereas both TRPM4 and TRPM5 have been implicated in mediating slow inward currents in cortical neurons (Lei et al., 2014) and in cerebellar Purkinje cells (Y. S. Kim et al., 2013). We found that, in the presence of the TRP channel inhibitor FFA $(100 \mu \mathrm{M})$, PF was completely eliminated (apamin: $92 \%$, apamin + FFA: $0 \%, n=17, \chi_{(1)}^{2}=46.6, p=10^{-20}$; Fig. $\left.6 A-C\right)$. Next, we examined the effects of the broad-spectrum inhibitor 2-APB, which among TRP channels blocks TRPC7 and TRPM2, but does not inhibit TRPM4 or TRPM5. 2-APB had no effect on PF (apamin: $92 \%$, apamin + 2-APB: $90 \%, n=10, \chi_{(1)}^{2}=0.4, p=0.54$; Fig. $6 B$ ), with plateau potential duration comparable to control conditions (apamin: $1108.5 \pm 126.6 \mathrm{~ms}$, apamin +2 -APB: $758 \pm 132.4 \mathrm{~ms}, t_{(49)}=1.3, p=0.22$; Fig. $6 C$ ), ruling out a role of TRPM2 or TRPC7 and suggesting that either TRPM4 or TRPM5 might mediate PF. Both channels are voltage-dependent, monovalent-selective, and require increases in intracellular $\mathrm{Ca}^{2+}$ for their activation (Launay et al., 2002; Nilius et al., 2003). We found that, in the presence of the TRPM4/5 antagonists 9-phenthranol (9-Phen, $100 \mu \mathrm{M}$ ) and glibenclamide (Glib, $100 \mu \mathrm{M}), P F$ was almost completely eliminated (apamin: $92 \%$, apamin +9 Phen: $15 \%, n=15, \chi_{(1)}^{2}=34.2, p=10^{-14}$, Glib: $0 \%, n=21$, $\chi_{(1)}^{2}=51.4, p=10^{-26}$; Fig. $\left.6 B\right)$. Next, we performed experiments using the recently developed selective TRPM4 antagonist CBA (Ozhathil et al., 2018). In the presence of CBA (50 $\mu \mathrm{M})$, PF was completely eliminated (apamin: 92\%, apamin + CBA: 0\%, $n=15, \quad \chi_{(1)}^{2}=44, p=10^{-17}$; Fig. $\left.6 A, B\right)$. Together, our results 
indicate that TRPM4 conductances mediate the plateau potential underlying PF.

Since increases in intracellular $\mathrm{Ca}^{2+}$ are required for TRPM4 activation, exogenous buffers, such as BAPTA, should eliminate $\mathrm{PF}$. However, due to the rundown of $\mathrm{PF}$, experiments relying on the infusion of $\mathrm{Ca}^{2+}$ chelators were not feasible. We therefore probed a possible $\mathrm{Ca}^{2+}$ requirement of $\mathrm{PF}$ by replacing extracellular $\mathrm{Ca}^{2+}$ with equimolar $\mathrm{Ba}^{2+} \cdot \mathrm{Ba}^{2+}$ passes through T-type $\mathrm{Ca}^{2+}$ channels and generates large inward currents (Huguenard and Prince, 1992), but, unlike $\mathrm{Ca}^{2+}$, does not lead to TRPM4 activation (Nilius et al., 2004; Yamaguchi et al., 2014). Under these conditions, brief depolarizing steps still led to prominent burst firing, indicating that T-type $\mathrm{Ca}^{2+}$ channel-dependent dendritic depolarizations were not affected (Fig. 6A). However, none of the cells displayed PF (apamin: $92 \%$, apamin $+\mathrm{Ba}^{2+}: 0 \%$, $n=15, \chi_{(1)}^{2}=44, p=10^{-17}$; Fig. $\left.6 B, C\right)$. These data further confirm that T-type $\mathrm{Ca}^{2+}$ channels alone are not sufficient to generate plateau potentials. Instead, our data suggest that T-type $\mathrm{Ca}^{2+}$ channel activation and the resulting $\mathrm{Ca}^{2+}$ increases lead to the activation of TRPM4 conductances and the generation of PF.

\section{Synaptic recruitment of muscarinic acetylcholine receptors suppresses $\mathrm{PF}$}

Finally, we examined the modulation of PF by synaptic activity. TRN neurons are the target of cholinergic afferents from the basal forebrain and brainstem (Hallanger and Wainer, 1988). Our previous studies have shown that ACh release leads to a biphasic postsynaptic response, with fast excitation mediated by nAChRs and slow- and long-lasting inhibition mediated by M2 muscarinic receptors (mAChRs) coupled $\mathrm{G}$ protein-gated inward rectifying $\mathrm{K}^{+}$channels (Sun et al., 2013). To examine whether cholinergic inputs can trigger PF in the TRN, we performed experiments using ChAT-ChR2-EYFP mice that selectively express ChR2 in cholinergic neurons (Zhao et al., 2011) and optogenetically evoked ACh release with light pulses $(1 \mathrm{~ms})$ centered over the recorded neuron. To avoid decay of PF, TRN neurons were recorded in loose-patch mode. Under these conditions, 2 of 5 neurons displayed PF (Fig. $7 A, C$ ). We reasoned that the activation of $\mathrm{mAChRs}$ and the resulting $\mathrm{G}$ protein-gated inward rectifying $\mathrm{K}^{+}$ activation might limit a full manifestation of PF. Indeed, following atropine application to block mAChRs, the duration of action potential firing was significantly prolonged in all neurons recorded (control: $213.5 \pm 94 \mathrm{~ms}$, atropine: $416.3 \pm 84.1 \mathrm{~ms}, t_{(4)}=7.1, p=$ 0.002; Fig. $7 A-C$ ), and the incidence of PF increased from $40 \%$ to $80 \%$. These data show that the activation of $\mathrm{K}^{+}$channels by synaptically released neuromodulators, such as ACh, can dynamically modulate the expression of PF.

\section{Discussion}

Here we have identified TRPM4 as the mechanism underlying PF in adult neurons of the TRN. Our data indicate that the large depolarizations and intracellular $\mathrm{Ca}^{2+}$ increases required for TRPM4 activation are mediated by T-type $\mathrm{Ca}^{2+}$ channels. PF was associated with robust slow oscillatory activity in thalamic circuits, which required fast synaptic transmission but did not rely on mGluR receptor signaling. Previous studies have shown that both TRN and thalamic relay neurons can act as cellular pacemakers for slow thalamic oscillations. Our present findings highlight intrathalamic circuits as an alternative mechanism capable of generating slow rhythmic activity.

\section{Mechanisms of PF in the TRN}

Our results extend recent work that has implicated TRPM4 in controlling neuronal excitability in cortex (Lei et al., 2014;
A
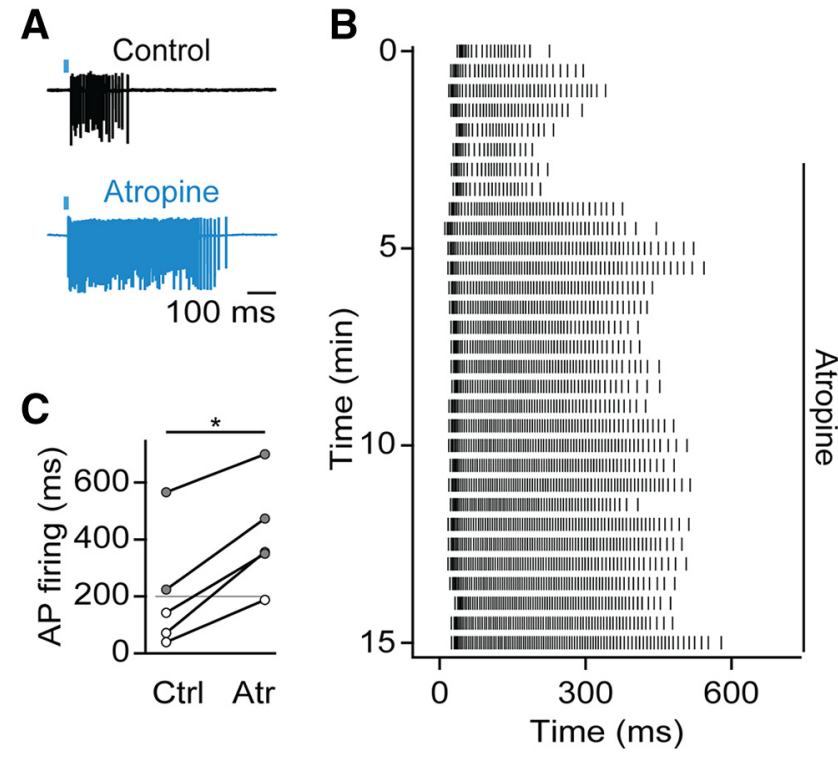

Figure 7. Synaptic recruitment of muscarinic AChRs suppresses PF. Recordings were conducted in slices of ChAT-ChR2-EYFP mice. $A$, Loose-patch recording from a TRN neuron showing brief barrage of ACh-evoked activity (black), which is prolonged following application of the mAChR antagonist atropine (10 $\mu \mathrm{m}$, blue). $\boldsymbol{B}$, Raster plot of ACh-evoked neuronal activity before and following atropine application, for the cell shown in $\boldsymbol{A}$. $\boldsymbol{C}$, Summary data quantifying the average duration of ACh-evoked action potential activity before and after atropine application $(n=5) .^{*} p<0.05$.

Riquelme et al., 2018), hippocampus (Menigoz et al., 2016), substantia nigra (Mrejeru et al., 2011), and brainstem (Picardo et al., 2019). A unique property of TRPM4 activation within physiological ranges is the requirement for both depolarization and large increases in intracellular $\mathrm{Ca}^{2+}$ concentration (Launay et al., 2002; Nilius et al., 2003, 2004). Since dendritic $\mathrm{Ca}^{2+}$ signals can experience decay under whole-cell conditions, this might partly explain why we consistently observed rundown of PF in the present study. Alternatively, recordings in whole-cell mode might have led to the dialysis of critical signaling molecules. TRPM4 conductances rapidly desensitize in excised patches (Zhang et al., 2005) and in whole-cell mode, but modulators such as PIP2 can restore TRPM4 activity. Additional investigations into the mechanisms of TRPM4 regulation under physiological conditions will be important.

What are the $\mathrm{Ca}^{2+}$ sources of TRPM4 activation? We found that pharmacological block of T-type $\mathrm{Ca}^{2+}$ channel using the specific antagonist TTA-P2 completely eliminated PF. In addition, replacing $\mathrm{Ca}^{2+}$ with $\mathrm{Ba}^{2+}$ abolished PF. These findings suggest that the $\mathrm{Ca}^{2+}$ increases required for TRPM4 activation are mediated by influx through T-type $\mathrm{Ca}^{2+}$ channels, although we cannot rule out a contribution of R-type $\mathrm{Ca}^{2+}$ channels (Zaman et al., 2011) or release from internal stores (Neyer et al., 2016). $\mathrm{Ca}_{\mathrm{V}} 3.3$ channels mediating $\mathrm{I}_{\mathrm{T}}$ are primarily expressed in the distal dendrites of TRN neurons, and their activation during burst firing results in large dendritic but more modest somatic $\mathrm{Ca}^{2+}$ signals (Crandall et al., 2010; Astori et al., 2011). This would suggest a dendritic location of TRPM4. In this scenario, membrane depolarizations necessary for TRPM4 activation would likely be mediated by synaptically generated T-type dependent $\mathrm{Ca}^{2+}$ spikes, which, in contrast to fast $\mathrm{Na}^{+}$action potentials, propagate effectively into TRN dendrites (Crandall et al., 2010; Connelly et al., 2015).

We found that, in the presence of apamin, PF could be observed in most recordings, suggesting that TRPM4 conductances are 
expressed in the large majority of TRN neurons. Thus, SK channels control both the initiation and duration of PF, likely due to the close functional association with T-type $\mathrm{Ca}^{2+}$ channels (Cueni et al., 2008). Similarly, we found that the synaptic activation of M2 muscarinic receptors curtailed the duration of PF. It is therefore likely that, under physiological conditions, TRPM4 activation and the generation of PF in a given neuron do not occur in an all-or-none manner, but instead are constantly regulated by multiple synaptic and intrinsic processes. For example, an increased likelihood and duration of PF might be promoted by mechanisms that increase T-type-mediated $\mathrm{Ca}^{2+}$ increases or directly facilitate TRPM4 activation, and curtailed by modulatory synaptic systems that reduce TRN excitability via opening of specific $\mathrm{K}$ conductances.

We want to emphasize that our findings do not provide clear evidence for a well-defined cell type that displays PF. Previous studies using molecular markers (Clemente-Perez et al., 2017) or firing patterns (Lee et al., 2007) described TRN neuronal subtypes that differ in the magnitude of T-type $\mathrm{Ca}^{2+}$-mediated currents, likely a critical factor in determining the incidence of PF in a given neuron. However, as outlined above, we predict that a range of mechanisms, including the spatial arrangement and density of synaptic and intrinsic conductances, and intracellular $\mathrm{Ca}^{2+}$ signaling pathways interact to control PF.

\section{Comparison with previous studies}

Plateau potentials and PF have been observed throughout the brain, including the thalamus, although in most cases there is little consensus on the underlying mechanisms (Zylberberg and Strowbridge, 2017). In vitro studies have reported plateau potentials in a fraction of neurons of the perigeniculate sector of the ferret TRN, with very similar properties as described here (U. Kim and McCormick, 1998). In contrast to our findings, plateau potentials were found to be TTX-sensitive, suggesting that $\mathrm{I}_{\mathrm{NaP}}$ was the underlying mechanism. Similar conclusions were reached in an in vivo study of TRN in anesthetized cats, which demonstrated block of plateau potentials using intracellular dialysis with QX-314 (Fuentealba et al., 2005). Here we find that in apamin a significant number of TRN neurons show plateau potentials, even in the presence of TTX. It is possible that, under physiological conditions, transient or persistent forms of voltagegated $\mathrm{I}_{\mathrm{Na}}$ indirectly aid PF by increasing activation of TRPM4 and T-type $\mathrm{Ca}^{2+}$ channels.

For both TRN and thalamic relay neurons, Group $1 \mathrm{mGluR}$ activation can trigger rhythmic forms of PF, mediated by the closure of a $\mathrm{K}^{+}$leak conductance, allowing the generation of a longlasting inward current mediated by the noninactivating portion of T-type $\mathrm{Ca}^{2+}$ channel conductance (Hughes et al., 2002; Blethyn et al., 2006). Our present findings differ from these results in four important aspects: First, PF did not require mGluR activation and the resulting closure of $\mathrm{K}^{+}$leak conductances. Second, in the absence of mGluR activation, PF did not occur in a cell-intrinsic manner but required fast synaptic inputs. Under our experimental conditions, both cholinergic inputs and bursts of glutamatergic thalamic inputs triggered PF, likely by generating global $\mathrm{Ca}^{2+}$ spikes (Connelly et al., 2015). Third, while T-type $\mathrm{Ca}^{2+}$ channels were important for the initiation of $\mathrm{PF}$, our results are inconsistent with a critical role of $\mathrm{I}_{\mathrm{T}}$ in generating long-lasting currents that lead to plateau potentials. We found that plateau potentials reached levels of $\sim-45 \mathrm{mV}$, for which T-type $\mathrm{Ca}^{2+}$ conductances approach full inactivation at steady state. Furthermore, the lack of PF in the presence of $\mathrm{Ba}^{2+}$, which should allow for the generation of a $\mathrm{I}_{\mathrm{T}}$-mediated window current (Huguenard and Prince, 1992), suggests that T-type $\mathrm{Ca}^{2+}$ currents alone are unlikely to mediate PF. Fourth, using the potent and selective antagonist CBA (Ozhathil et al., 2018), we showed that $\mathrm{I}_{\mathrm{CAN}}$ was essential for the generation of plateau potentials and was mediated by TRPM4. However, virtually all TRP antagonists used in previous studies have a number of nonspecific effects, so the validation of CBA as a selective TRPM4 antagonist under our experimental conditions will require independent confirmation.

\section{Mechanisms of slow thalamic oscillations}

Accumulating evidence indicates that both cortex and thalamus can generate oscillations in isolation, suggesting that rhythmic activity in the intact thalamocortical system results from the complex interplay of multiple distinct oscillators (Crunelli and Hughes, 2010). While there has been extensive research on the cortical mechanisms mediating slow rhythms, the nature of thalamic pacemakers is less well understood. Previous work has shown that both TRN and relay neurons are capable of generating cell-intrinsic rhythms in the $1 \mathrm{~Hz}$ range, but only under conditions of postsynaptic mGluR activation (Hughes et al., 2002; Blethyn et al., 2006). Under physiological conditions, this would require sustained corticothalamic activity, indicating that both thalamic cell types act as conditional oscillators. Our findings derived from adult thalamic slices highlight an alternative mechanism and suggest that networks of TRN and VB cells can generate robust and long-lasting slow oscillatory activity, mediated by powerful bidirectional synaptic connectivity (Gentet and Ulrich, 2003; Pinault, 2004; Pita-Almenar et al., 2014). We observed an inverse relationship between TRN firing duration and oscillatory frequency. It is therefore tempting to suggest that changes in TRN activity, as seen during PF, act to reduce the frequency of thalamic oscillations, via recruitment of $\mathrm{GABA}_{\mathrm{B}} \mathrm{Rs}$ (U. Kim et al., 1997) or extrasynaptic high-affinity $\mathrm{GABA}_{\mathrm{A}} \mathrm{Rs}$ (Herd et al., 2013), thereby changing the latency to rebound burst generation (Schofield et al., 2009).

Our network data suggest that robust thalamic rhythmicity can occur in the absence of precise synchrony, highlighting that both processes can occur independently. While thalamic oscillatory activity is commonly referred to as synchronous (Fogerson and Huguenard, 2016), there have been few studies that have directly examined the degree of precise thalamic synchronization during distinct behavioral states. Our current data showing a lack of precise synchrony in local thalamic circuits confirm previous findings (Pita-Almenar et al., 2014) and indicate that the variability in TRN firing might act as an additional factor in preventing synchrony in isolated thalamic networks. As has been suggested (Contreras and Steriade, 1996), this would argue that synchronization of thalamic networks is primarily regulated by afferent inputs, particularly from cortex.

\section{References}

Agmon A, Connors BW (1991) Thalamocortical responses of mouse somatosensory (barrel) cortex in vitro. Neuroscience 41:365-379.

Astori S, Wimmer RD, Prosser HM, Corti C, Corsi M, Liaudet N, Volterra A, Franken P, Adelman JP, Lüthi A (2011) The Cav3.3 calcium channel is the major sleep spindle pacemaker in thalamus. Proc Natl Acad Sci USA 108:13823-13828.

Beenhakker MP, Huguenard JR (2009) Neurons that fire together also conspire together: is normal sleep circuitry hijacked to generate epilepsy? Neuron 62:612-632.

Ben-Mabrouk F, Tryba AK (2010) Substance P modulation of TRPC3/7 channels improves respiratory rhythm regularity and ICAN-dependent pacemaker activity. Eur J Neurosci 31:1219-1232. 
Blethyn KL, Hughes SW, Tóth TI, Cope DW, Crunelli V (2006) Neuronal basis of the slow $(<1 \mathrm{~Hz})$ oscillation in neurons of the nucleus reticularis thalami in vitro. J Neurosci 26:2474-2486.

Bryant AS, Li B, Beenhakker MP, Huguenard JR (2009) Maintenance of thalamic epileptiform activity depends on the astrocytic glutamate-glutamine cycle. J Neurophysiol 102:2880-2888.

Clemente-Perez A, Makinson SR, Higashikubo B, Brovarney S, Cho FS, Urry A, Holden SS, Wimer M, Dávid C, Fenno LE, Acsády L, Deisseroth K, Paz JT (2017) Distinct thalamic reticular cell types differentially modulate normal and pathological cortical rhythms. Cell Rep 19:2130-2142.

Connelly WM, Crunelli V, Errington AC (2015) The global spike: conserved dendritic properties enable unique $\mathrm{Ca}^{2+}$ spike generation in low-threshold spiking neurons. J Neurosci 35:15505-15522.

Contreras D, Steriade M (1996) Synchronization of low-frequency rhythms in corticothalamic networks. Neuroscience 76:11-24.

Crabtree JW, Lodge D, Bashir ZI, Isaac JTR (2013) GABAA, NMDA and mGlu2 receptors tonically regulate inhibition and excitation in the thalamic reticular nucleus. Eur J Neurosci 37:850-859.

Crandall SR, Govindaiah G, Cox CL (2010) Low-threshold $\mathrm{Ca}^{2+}$ current amplifies distal dendritic signaling in thalamic reticular neurons. J Neurosci 30:15419-15429.

Crunelli V, Hughes SW (2010) The slow (1 Hz) rhythm of non-REM sleep: a dialogue between three cardinal oscillators. Nat Neurosci 13:9-17.

Crunelli V, Lörincz ML, Connelly WM, David F, Hughes SW, Lambert RC, Leresche N, Errington AC (2018) Dual function of thalamic low-vigilance state oscillations: rhythm-regulation and plasticity. Nat Rev Neurosci 19:107-118.

Cueni L, Canepari M, Luján R, Emmenegger Y, Watanabe M, Bond CT, Franken P, Adelman JP, Lüthi A (2008) T-type $\mathrm{Ca}^{2+}$ channels, SK2 channels and SERCAs gate sleep-related oscillations in thalamic dendrites. Nat Neurosci 11:683-692.

David F, Schmiedt JT, Taylor HL, Orban G, Di Giovanni G, Uebele VN, Renger JJ, Lambert RC, Leresche N, Crunelli V (2013) Essential thalamic contribution to slow waves of natural sleep. J Neurosci 33:19599-19610.

Diekelmann S, Born J (2010) The memory function of sleep. Nat Rev Neurosci 11:114-126.

Fernandez LM, Vantomme G, Osorio-Forero A, Cardis R, Béard E, Lüthi A (2018) Thalamic reticular control of local sleep in mouse sensory cortex. Elife 7:1-25.

Fogerson PM, Huguenard JR (2016) Tapping the brakes: cellular and synaptic mechanisms that regulate thalamic oscillations. Neuron 92:687-704.

Fuentealba P, Timofeev I, Bazhenov M, Sejnowski TJ, Steriade M (2005) Membrane bistability in thalamic reticular neurons during spindle oscillations. J Neurophysiol 93:294-304.

Gentet LJ, Ulrich D (2003) Strong, reliable and precise synaptic connections between thalamic relay cells and neurones of the nucleus reticularis in juvenile rats. J Physiol 546:801-811.

Halassa MM, Siegle JH, Ritt JT, Ting JT, Feng G, Moore CI (2011) Selective optical drive of thalamic reticular nucleus generates thalamic bursts and cortical spindles. Nat Neurosci 14:1118-1120.

Hallanger AE, Wainer BH (1988) Ultrastructure of ChAT-immunoreactive synaptic terminals in the thalamic reticular nucleus of the rat. J Comp Neurol 278:486-497.

Hartmann J, Dragicevic E, Adelsberger H, Henning HA, Sumser M, Abramowitz J, Blum R, Dietrich A, Freichel M, Flockerzi V, Birnbaumer L, Konnerth A (2008) TRPC3 channels are required for synaptic transmission and motor coordination. Neuron 59:392-398.

Hefft S, Jonas P (2005) Asynchronous GABA release generates long-lasting inhibition at a hippocampal interneuron-principal neuron synapse. Nat Neurosci 8:1319-1328.

Herd MB, Brown AR, Lambert JJ, Belelli D (2013) Extrasynaptic GABAA receptors couple presynaptic activity to postsynaptic inhibition in the somatosensory thalamus. J Neurosci 33:14850-14868.

Hughes SW, Cope DW, Blethyn KL, Crunelli V (2002) Cellular mechanisms of the slow $(<1 \mathrm{~Hz})$ oscillations in thalamocortical neurons in vitro. Neuron 33:947-958.

Huguenard JR, McCormick DA (2007) Thalamic synchrony and dynamic regulation of global forebrain oscillations. Trends Neurosci 30:350-356.

Huguenard JR, Prince DA (1992) A novel T-type current underlies prolonged $\mathrm{Ca}^{2+}$-dependent burst firing in GABAergic neurons of rat thalamic reticular nucleus. J Neurosci 12:3804-3817.
Huguenard JR, Prince DA (1994) Intrathalamic rhythmicity studied in vitro: nominal T-current modulation causes robust antioscillatory effects. J Neurosci 14:5485-5502.

Kim U, McCormick DA (1998) Functional and ionic properties of a slow afterhyperpolarization in ferret perigeniculate neurons in vitro. J Neurophysiol 80:1222-1235.

Kim U, Sanchez-Vives MV, McCormick DA (1997) Functional dynamics of GABAergic inhibition in the thalamus. Science 278:130-134.

Kim YS, Kang E, Makino Y, Park S, Shin JH, Song H, Launay P, Linden DJ (2013) Characterizing the conductance underlying depolarizationinduced slow current in cerebellar Purkinje cells. J Neurophysiol 109:1174-1181.

Launay P, Fleig A, Perraud AL, Scharenberg AM, Penner R, Kinet JP (2002) TRPM4 is a $\mathrm{Ca}^{2+}$-activated nonselective cation channel mediating cell membrane depolarization. Cell 109:397-407.

Lee CR, Machold RP, Witkovsky P, Rice ME (2013) TRPM2 channels are required for NMDA-induced burst firing and contribute to $\mathrm{H}_{2} \mathrm{O}_{2}$-dependent modulation in substantia nigra pars reticulata GABAergic neurons. J Neurosci 33:1157-1168.

Lee SH, Govindaiah G, Cox CL (2007) Heterogeneity of firing properties among rat thalamic reticular nucleus neurons. J Physiol 582:195-208.

Lei YT, Thuault SJ, Launay P, Margolskee RF, Kandel ER, Siegelbaum SA (2014) Differential contribution of TRPM4 and TRPM5 nonselective cation channels to the slow afterdepolarization in mouse prefrontal cortex neurons. Front Cell Neurosci 8:1-14.

Lemieux M, Chen JY, Lonjers P, Bazhenov M, Timofeev I (2014) The impact of cortical deafferentation on the neocortical slow oscillation. J Neurosci 34:5689-5703.

Lüthi A (2014) Sleep spindles: Where they come from, what they do. J Neurosci 34:5689-5703.

Menigoz A, Ahmed T, Sabanov V, Philippaert K, Pinto S, Kerselaers S, Segal A, Freichel M, Voets T, Nilius B, Vennekens R, Balschun D (2016) TRPM4-dependent post-synaptic depolarization is essential for the induction of NMDA receptor-dependent LTP in CA1 hippocampal neurons. Pflugers Arch 468:593-607.

Mrejeru A, Wei A, Ramirez JM (2011) Calcium-activated non-selective cation currents are involved in generation of tonic and bursting activity in dopamine neurons of the substantia nigra pars compacta. J Physiol 589:2497-2514.

Neske GT (2016) The slow oscillation in cortical and thalamic networks: mechanisms and functions. Front Neural Circuits 9:88.

Neyer C, Herr D, Kohmann D, Budde T, Pape HC, Coulon P (2016) mGluRmediated calcium signalling in the thalamic reticular nucleus. Cell Calcium 59:312-323.

Nilius B, Prenen J, Droogmans G, Voets T, Vennekens R, Freichel M, Wissenbach U, Flockerzi V (2003) Voltage dependence of the $\mathrm{Ca}^{2+}$-activated cation channel TRPM4. J Biol Chem 278:30813-30820.

Nilius B, Prenen J, Voets T, Droogmans G (2004) Intracellular nucleotides and polyamines inhibit the $\mathrm{Ca}^{2+}$-activated cation channel TRPM4b. Pflugers Arch 448:70-75.

Ozhathil LC, Delalande C, Bianchi B, Nemeth G, Kappel S, Thomet U, RossKaschitza D, Simonin C, Rubin M, Gertsch J, Lochner M, Peinelt C, Reymond JL, Abriel H (2018) Identification of potent and selective small molecule inhibitors of the cation channel TRPM4. Br J Pharmacol 175:2504-2519.

Perkins KL (2006) Cell-attached voltage-clamp and current-clamp recording and stimulation techniques in brain slices. J Neurosci Methods 154:1-18.

Picardo MC, Sugimura YK, Dorst KE, Kallurkar PS, Akins VT, Ma X, Teruyama R, Guinamard R, Kam K, Saha MS, Del Negro CA (2019) Trpm4 ion channels in pre-Bötzinger complex interneurons are essential for breathing motor pattern but not rhythm. PLoS Biol 17:e2006094.

Pinault D (2004) The thalamic reticular nucleus: structure, function and concept. Brain Res Brain Res Rev 46:1-31.

Pita-Almenar JD, Yu D, Lu HC, Beierlein M (2014) Mechanisms underlying desynchronization of cholinergic-evoked thalamic network activity. J Neurosci 34:14463-14474.

Rigas P, Castro-Alamancos MA (2007) Thalamocortical up states: differential effects of intrinsic and extrinsic cortical inputs on persistent activity. J Neurosci 27:4261-4272.

Riquelme D, Silva I, Philp AM, Huidobro-Toro JP, Cerda O, Trimmer JS, Leiva-Salcedo E (2018) Subcellular localization and activity of TRPM4 in medial prefrontal cortex layer 2/3. Front Cell Neurosci 12:12. 
Sachdeva R, Schlotterer A, Schumacher D, Matka C, Mathar I, Dietrich N, Medert R, Kriebs U, Lin J, Nawroth P, Birnbaumer L, Fleming T, Hammes HP, Freichel M (2018) TRPC proteins contribute to development of diabetic retinopathy and regulate glyoxalase 1 activity and methylglyoxal accumulation. Mol Metab 9:156-167.

Sanchez-Vives MV, McCormick DA (2000) Cellular and network mechanisms of rhythmic recurrent activity in neocortex. Nat Neurosci 3:10271034.

Schofield CM, Kleiman-Weiner M, Rudolph U, Huguenard JR (2009) A gain in GABA A receptor synaptic strength in thalamus reduces oscillatory activity and absence seizures. Proc Natl Acad Sci USA 106:7630-7635.

Steriade M, Timofeev I (2003) Neuronal plasticity in thalamocortical networks during sleep and waking oscillations. Neuron 37:563-576.

Steriade M, Contreras D, Dossi RC, Nunez A (1993a) The slow $(<1 \mathrm{~Hz})$ oscillation in reticular thalamic and thalamocortical neurons: scenario of sleep rhythm generation in interacting thalamic and neocortical networks. J Neurosci 13:3284-3299.

Steriade M, Nunez A, Amzica F (1993b) A novel slow $(<1 \mathrm{~Hz})$ oscillation of neocortical neurons in vivo: depolarizing and hyperpolarizing components. J Neurosci 13:3252-3265.

Stroh A, Adelsberger H, Groh A, Rühlmann C, Fischer S, Schierloh A, Deisseroth K, Konnerth A (2013) Making waves: initiation and propagation of corticothalamic $\mathrm{Ca}^{2+}$ waves in vivo. Neuron 77:1136-1150.

Sun YG, Pita-Almenar JD, Wu CS, Renger JJ, Uebele VN, Lu HC, Beierlein M (2013) Biphasic cholinergic synaptic transmission controls action potential activity in thalamic reticular nucleus neurons. J Neurosci 33:2048-2059.

Sun YG, Rupprecht V, Zhou L, Dasgupta R, Seibt F, Beierlein M (2016) mGluR1 and mGluR5 synergistically control cholinergic synaptic transmission in the thalamic reticular nucleus. J Neurosci 36:7886-7896.

Tian J, Zhu M (2018) GABAB receptors augment TRPC3-mediated slow excitatory postsynaptic current to regulate cerebellar Purkinje neuron response to Type 1 metabotropic glutamate receptor activation. Cells 7:90.

Ting JT, Daigle T, Chen Q, Feng G (2014) Acute brain slice method for adult and aging animals: application of targeted patch clamp analysis and optogenetics. In: Methods in molecular biology (MartinaM, Taverna S, eds), pp 221-242. New York: Humana.

Varga AW, Wohlleber ME, Giménez S, Romero S, Alonso JF, Ducca EL, Kam K, Lewis C, Tanzi EB, Tweardy S, Kishi A, Parekh A, Fischer E, Gumb T, Alcolea D, Fortea J, Lleó A, Blennow K, Zetterberg H, Mosconi $\mathrm{L}$, et al. (2016) Reduced slow-wave sleep is associated with high cerebrospinal fluid A $\beta 42$ levels in cognitively normal elderly. Sleep 39:20412048.

Williams SR, Tóth TI, Turner JP, Hughes SW, Crunelli V (1997) The "window" component of the low threshold $\mathrm{Ca}^{2+}$ current produces input signal amplification and bistability in cat and rat thalamocortical neurones. J Physiol 505:689-705.

Yamaguchi S, Tanimoto A, Otsuguro KI, Hibino H, Ito S (2014) Negatively charged amino acids near and in transient receptor potential (TRP) domain of TRPM4 channel are one determinant of its $\mathrm{Ca}^{2+}$ sensitivity. J Biol Chem 289:35265-35282.

Zaman T, Lee K, Park C, Paydar A, Choi JH, Cheong E, Lee CJ, Shin HS (2011) CaV2.3 channels are critical for oscillatory burst discharges in the reticular thalamus and absence epilepsy. Neuron 70:95-108.

Zhang Z, Okawa H, Wang Y, Liman ER (2005) Phosphatidylinositol 4,5-bisphosphate rescues TRPM4 channels from desensitization. J Biol Chem 280:39185-39192.

Zhao S, Ting JT, Atallah HE, Qiu L, Tan J, Gloss B, Augustine GJ, Deisseroth K, Luo M, Graybiel AM, Feng G (2011) Cell type-specific channelrhodopsin-2 transgenic mice for optogenetic dissection of neural circuitry function. Nat Methods 8:745-755.

Zylberberg J, Strowbridge BW (2017) Mechanisms of persistent activity in cortical circuits: possible neural substrates for working memory. Annu Rev Physiol 40:603-627. 